\title{
MINAT INVESTOR MUDA DALAM BERINVESTASI REKSA DANA DI BUKALAPAK
}

\author{
Intan Nurul Izzati ${ }^{1}$, Dwi Nor Safitri ${ }^{2}$, Kharis Fadlullah Hana ${ }^{3}$ \\ ${ }^{1}$ Ekonomi Syariah, Ekonomi dan Bisnis Islam, IAIN Kudus \\ ${ }^{2}$ Ekonomi Syariah, Ekonomi dan Bisnis Islam, IAIN Kudus \\ ${ }^{3}$ Ekonomi Syariah, Ekonomi dan Bisnis Islam, IAIN Kudus \\ intanntnrl@gmail.com ${ }^{1}$, dwisafitri951@gmail.com² ${ }^{2}$ kharis@iainkudus.ac.id ${ }^{3}$.
}

\begin{abstract}
ABSTRAK
Faktor yang menjadi penyebab ketertarikan atau minat para investor muda dapat melakukan investasi pada reksa dana di BukaLapak. Tujuan penelitian ini adalah untuk mengembangkan penelitian sebelumnya yang belum membahas mengenai reksa dana pada BukaLapak dan agar dapat mengetahui faktor apa saja yang melatarbelakangi para investor muda dapat tertarik atau berminat dalam melakukan investasi reksa dana BukaLapak. Peneliti menggunakan metode penelitian kualitatif dengan jenis penelitian lapangan, yang menggunakan sumber data primer dengan teknik pengumpulan data wawancara. Hasil dari penelitian ini menyebutkan bahwa minat para investor muda reksa dana BukaLapak di sebabkan oleh faktor kemudahan dalam operasional investasi Reksa Dana Bukalapak dan faktor dana atau modal yang terjangkau yang dibutuhkan dalam investasi Reksa Dana BukaLapak. Jadi, para investor muda reksa dana Bukalapak dapat berminat melakukan investasi ini karena di sebabkan oleh faktor kemudahan operasional dan faktor modal dana yang terjangkau.
\end{abstract}

Kata Kunci: Minat, Investasi, Reksa Dana, BukaLapak.

\begin{abstract}
Factors that are the cause of interest or interest of young investors can invest in mutual funds in BukaLapak. The purpose of this study is to develop previous research that does not discuss mutual funds in BukaLapak and in order to find out what factors are behind the investors who can be interested or interested in investing in BukaLapak mutual funds. Researchers used qualitative research methods with the type of field research, which uses primary data sources with interview data collection techniques. The Bukalapak Mutual Fund and the fund or capital factors needed in the BukaLapak Mutual Fund investment. So, young investors of Bukalapak mutual funds can be interested in making this investment because they are caused by operational ease factors and affordable capital funds.
\end{abstract}

Keywords: Interest, Investment, Mutual Fund, BukaLapak.

\section{A. PENDAHULUAN}

Saat ini kemajuan perekonomian di Indonesia, pasar modal adalah pilihan terbaik untuk berinvestasi (Marselo Valentino Geovani Pariela, 2017). Investasi merupakan pengaitan sumber-sumber dalam jangka panjang untuk memperoleh hasil laba dimasa yang akan 
datang (Munawaroh \& Sugiyono, 2019). Investasi dapat dilakukan di pasar modal dengan berbagai instrumen yang ada, salah satunya adalah reksa dana. Reksa dana menjadi salah satu instrumen investasi yang menggoda, karena masyarakat khususnya generasi muda yang memiliki pengetahuan terbatas mengenai investasi di pasar modal terutama pada reksa dana, masih tetap bisa melakukan investasi, dengan mengalokasikan dananya kepada manajer investasi yang notabenenya sudah ahli dalam bidangnya (Ary Satria Pamungkas, Herlina Budiono, Hendra Wiyanto, 2019).

Meskipun demikian, generasi muda masih sering kali bingung dan belum mengerti bagaimana cara untuk memulai dan melakukan investasi, khususnya investasi pada instrumen reksa dana. Reksa dana merupakan suatu wadah berkumpulnya para investor untuk menyetorkan dana atau modal yang selanjutnya akan dikelola oleh manajer investasi yang notabenenya sudah ahli dalam bidangnya (Endang samsul arifin, 2017). Padahal di era teknologi digital saat ini masyarakat atau investor akan lebih mudah dalam berinvestasi reksa dana yang dapat dilakukan melalui website atau aplikasi secara online, salah satu contoh aplikasi yang menyediakan reksa dana secara online adalah BukaLapak. Banyaknya investasi online yang tidak bertanggung jawab dan illegal membuat masyarakat beranggapan negatif atau kurang baik. Hal ini menyebabkan masyarakat enggan berinvestasi (Ary Satria Pamungkas, Herlina Budiono, Hendra Wiyanto, 2019).

Berdasarkan penelitian yang telah dilakukan oleh Naili Rahmawati dan Any Tsalasatul Fitriyah (2016) hanya membahas tentang sebagian besar investor dalam penelitian tersebut berminat untuk berinvestasi efek syariah pada pasar modal syariah. minat tersebut dipengaruhi oleh adanya kehalalan tingkat bagi hasil yang akan diperoleh, sedangkan sebagian kecil investor dalam penelitian tersebut belum berminat untuk berinvestasi di pasar modal syariah, dengan latarbelakang kurangnya pengetahuan tentang investasi (Naili Rahmawati, 2016). Sedangkan dalam penelitian Tiar Lina Situngkir hanya menjelaskan bahwa masyarakat yang ingin mulai melakukan investasi reksa dana bisa melalui lembaga keuangan atau bank-bank pemeritah maupun swasta. Seperti kantor cabang di setiap wilayah daerah, yang pelayanan pembeliannya hanya bisa dilayani oleh staf khusus yang melayani pembelian surat berharga yang tersedia hanya di kantor cabang bank pemerintah dan swasta. Akan tetapi, penelitian-penelitian diatas belum menjelaskan secara jelas tentang investasi reksa dana juga bisa dilakukan dengan lebih mudah secara online pada aplikasi BukaLapak. Akan tetapi, penelitian tersebut menjelaskan bahwa pembelian reksa dana hanya dilakukan pada lembaga keuangan saja (Tiar Lina Situngkir, 2019). Padahal di era teknologi yang semakin canggih seperti saat ini pembelian reksa dana juga bisa dilakukan dengan mudah, kapanpun dan dimanapun melalui website atau aplikasi secara online, seperti salah satunya pada aplikasi Bukalapak.

Berdasarkan penelitian-penelitian diatas yang telah disebutkan, adanya kekurangan dalam membahas mengenai minat dalam berinvestasi reksa dana secara online, maka peneliti bermaksud untuk melakukan penelitian guna mengembangkan penelitian sebelumnya yang akan membahas tentang Minat Investor Muda dalam Berinvestasi Reksa Dana di Bukalapak.

\section{B. METODE PENELITIAN}

Jenis penelitian disini menggunakan jenis penelitian lapangan (field research) karena peneliti berperan secara langsung dalam penelitian. Penelitian lapangan (field reseaech) merupakan suatu penelitian yang dilakukan 
secara sistematis dengan mengangkat data yang ada di lapangan (Suharismi Arikunto, 1995). Dalam penelitian ini peneliti menggunakan media online melalui percakapan via whatsapp dikarenakan akhir-akhir ini terproteksi adanya wabah covid-19. Metode yang dipakai dalam penelitian yang berjudul minat investor muda dalam berinvestasi reksa dana di BukaLapak adalah penelitian kualitatif. Penelitian kualitatif adalah penelitian yang menggunakan latar alamiah dengan maksud menafsirkan fenomena yang terjadi dan di lakukan dengan jalan melibatkan berbagai metode yang ada (Anggito \& Setiawan, 2018). Sumber data yang digunakan dalam penelitian ini yakni data primer. Sumber data primer adalah sumber data yang langsung memberikan data kepada pengumpul data atau peneliti (Regina Singestecia, 2018). Data ini didapatkan dari wawancara kepada objek penelitian ini yaitu investor muda untuk mendapatkan data mengenai minat investor muda dalam berinvestasi reksa dana di BukaLapak. Tehnik pengumpulan data menggunakan metode wawancara (interview). Wawancara merupakan metode untuk mendapatkan informasi untuk tujuan penelitian dengan tanya jawab tatap muka antara peneliti dengan narasumber (Edi, 2016). Untuk pengumpulan data primer, digunakan tehnik wawancara yang dilakukan terhadap target yang dituju atau yang bersangkutan. Tujuannya yakni guna mendapatkan data yang valid. Tehnik wawancara dalam penelitian ini merupakan proses mendapatkan keterangan untuk tujuan penelitian melalui Tanya jawab secara online via whatsapp antara peneliti dengan narasumber dengan menggunakan alat yang disebut interview guide (panduan wawancara).

\section{HASIL DAN PEMBAHASAN}

Dalam Undang-undang Pasar Modal No. 8 Tahun 1995 Pasal 1 ayat (27), bahwasannya Reksa dana merupakan wadah yang di pergunakan untuk menghimpun dana dari masyarakat pemodal untuk selanjutnya di investasikan dalam portofolio efek oleh manajer investasi (Aji Darusman, 2019). Selama ini reksa dana masih kurang di minati oleh generasi muda dikarenakan, minimnya pengetahuan yang dimiliki mengenai investasi pada pasar modal terutama di reksa dana. Hal ini di latar belakangi oleh masih sulitnya peneliti menemukan seorang investor reksa dana saat pencarian narasumber dalam penelitian ini, karena sebagian besar generasi muda saat ini berinvestasi pada saham, hanya sebagian kecil saja generasi muda yang sudah mengenal dan berinvestasi pada reksa dana.

Dari hasil wawancara yang sudah peneliti lakukan kepada 5 investor muda pada Reksa dana BukaLapak, dengan nama narasumber: Asror Midkhal, Muhammad Naufal Izza, Abdullah Fakhri Hisyam, Andi Fandy, dan Ilham St. Dengan hasil bahwasannya:

a. Persepsi investor tentang investasi Reksa dana BukaLapak. 
Persepsi merupakan sebuah proses dimulai dari penglihatan menjadi bentuk tanggapan yang terjadi dalam seseorang sehingga seseorang sadar dengan segala sesuatu yang dilakukan. Persepsi investor mengenai reksa dana BukaLapak adalah salah satu instrumen investasi di pasar modal yang cukup aman, sangat bagus dan mudah dalam penggunaan, dan operasionalnya yang tidak begitu sulit untuk dilakukan apalagi bagi seorang investor pemula. Hal ini dibuktikan oleh hasil wawancara dengan narasumber yaitu saudara Asror Midkhal yang menyatakan bahwa:,

"Investasi Reksa dana pada aplikasi BukaLapak menurut saya cukup aman, karena transaksi keuangannya masuk ke ATM".

Hal ini di dukung oleh sosialisasi yang dilakukan BukaLapak dengan Otoritas Jasa Keuangan (OJK) dan CIMB Principal asset Management yang mensosialisasikan keamanan dalam melakukan investasi pada reksa dana di Semarang. Dengan acara yang bertema "Bukareksa Produk Investasi untuk Rakyat" pelapak (pemilik akun BukaLapak) di dorong lebih melek investasi reksa dana. Dalam sosialisasi ini Gahayu Handari (Business Development Manager BukaLapak), mengatakan bahwa:

"Lewat semangat dan misi UKM, kami ingin menumbuhkan semangat berinvestasi secara mudah dan aman kepada para pelapak serta masyarakat Indonesia melalui BukaReksa, produk investasi yang aman, mudah dan terjangkau". (https://reksadanacommunity.com/berinve stasi-reksa-dana-kini-lebih-mudah-di-fiturbukareksa-di-aplikasi-bukalapak/)

Selain pendapat yang di paparkan diatas, keamanan dalam berinvestasi reksa dana BukaLapak juga di dukung oleh kelebihan dalam investasi reksa dana bukalapak,

(https://asambackpacker01.wordpress.com Ltag/pengalaman-bukareksa-di-bukalapak/) yang menyatakan :

"Investasi Reksa dana bukalapak di atur ketat oleh OJK, sebelum dipasarkan harus dilaporkan dan di setujui oleh OJK, investasi ini juga aman dan transparan karena dana di bank custodian bukan di manajemen investasi. Kinerja NAB di laporkan harian di media dan laporan bulanannya ke investor".

Hal ini pun didukung oleh pengalaman seorang investor reksa dana BukaLapak yakni saudara Muhammad Miftahul Ulum pada

(http://www.muhammadmiftahululum.co $\underline{m} / 2017 / 07 /$ pengalaman-reksadana-pasaruang-di.html?m=1) yang menyatakan bahwa "investasi reksadana BukaLapak sudah pasti aman. Kenapa bisa begitu, sebab OJK (Otoritas Jasa Keuangan) akan menjaga dana kita dari kejahatan investasi. Pasti di jamin dana kita oleh OJK" 
Pendapat lain mengenai persepsi di ungkapkan oleh narasumber Hisyam dan Ilham St, yang menyatakan bahwa:

"Investasi Reksa dana Bukalapak ini Menurut saya sangatlah bagus, karena memudahkan masyarakat untuk mengenal produk-produk investasi".

Pernyataan tersebut sesuai dengan data yang disediakan pada aplikasi Bukalapak bahwasannya prosedur investasinya sangatlah simple dan mudah dipahami. Hal ini dibuktikan oleh adanya sebuah penelitian yang telah dilakukan oleh Muhamad Zulvan Aulia, yang memang dijelaskan dalam jurnal tersebut bahwa investasi melalui instrumen reksa dana berkembang sangat pesat. Transaksi reksa dana kini bisa dilakukan dengan mudah melalui aplikasi digital (mobile phone) dari perusahaan BukaLapak. Tujuannya tidak lain untuk membuka akses dan kemudahan bagi masyarakat untuk berinvestasi pada pasar modal Indonesia (Aulia, n.d.). Hal ini di dukung oleh penelitian Tiar Lina Situngkir, bahwasannya dari penelitian tersebut menunjukkan adanya pemahaman tentang reksa dana yang di dapat oleh peserta sosialisasi,, yang mana penelitian ini memberikan dampak positif yang signifikan pada peningkatan peserta dalam mengenal dan memahami surat berharga reksa dana yang dapat menjadi wadah investasi di masa mendatang" (Tiar Lina Situngkir, 2019). b. Minat Investor dalam berinvestasi Reksa dana BukaLapak

Ketertarikan atau minat seorang investor dalam melakukan investasi pada salah satu instrumen di pasar modal yakni reksa dana, terutama pada investasi reksa dana di BukaLapak ini dapat di latarbelakangi dan disebabkan oleh suatu hal yakni dengan adanya faktor kemudahan operasional, hal ini dibuktikan oleh hasil wawancara dengan beberapa investor pada reksa dana BukaLapak berikut:

Adapun pendapat yang di ungkapkan oleh narasumber Naufal, menyatakan bahwa:

"Investasi Reksa dana di BukaLapak ini cukup mudah dan simple, jadi bagi investor pemula pun tidak merasa kesulitan dalam mengoperasikannya".

Hal ini di dukung oleh teori, Qamruzzaman yang menyatakan bahwa, reksa dana memiliki keuntungan dalam hal variasi, fleksibilitas, diversifikasi, dan likuiditas. reksa Dana juga memiliki kapabilitas untuk solusi bagi investor yang memiliki keterbatasan atau minim pengetahuan (Md. Qamruzzaman, 2014).

Adapun pendapat lain dari narasumber, yaitu Ilham St dan Andi Fandy yang menyatakan bahwa:

"Investasi pada Reksa dana BukaLapak ini proses transaksi dan operasionalnya cukup simpel, mudah dan praktis, serta 
modal awalnya pun yang dibutuhkan tidak banyak".

Artinya, minat investor reksa dana di BukaLapak ini, di sebabkan dan di latarbelakangi oleh adanya faktor kemudahan dalam operasionalnya, yang menurut mereka berinvestasi reksa dana di BukaLapak ini sangat simple dan tidak begitu sulit apalagi bagi investor pemula yang memiliki keterbatasan pengetahuan tentang investasi ini. Hal ini sesuai dengan penelitian yang dilakukan oleh Muhamad Zulvan Aulia yang menyatakan bahwa sekarang investasi reksa dana dapat ditemukan melalui aplikasi handphone. Berkembangnya elektronik komersial (Ecommerce) adalah bentuk pondasi yang mendukung pertumbuhan investasi, termasuk reksa dana, disebabkan oleh adanya kemudahan dalam pengoperasiannya dan simpel dapat mendorong minat investor untuk melakukan investasi reksa dana di aplikasi BukaLapak (Aulia, n.d.).

c. Modal awal investor dalam berinvestasi Reksa dana BukaLapak.

Investasi pada reksa dana di aplikasi BukaLapak adalah investasi yang cukup mudah dan investasi yang tidak memerlukan dana yang cukup besar, karena hanya dengan dana yang minimal atau kecil sudah bisa melakukan investasi ini, hal ini sesuai dengan sebagian besar narasumber dalam penelitian ini menggunakan modal atau dana awal yang cukup minim yakni di bawah Rp 500.000,sudah bisa berinvestasi pada Reksa dana BukaLapak.

Teori menyatakan bahwa para investor dapat termotivasi dalam berinvestasi reksa dana yakni dengan adanya "prinsip kenyamanan" yang dijamin dan juga reksa dana merupakan 'pintu gerbang' bagi para investor untuk akses dalam melakukan investasi pada perusahaan atau emiten besar walaupun dengan dana atau modal investasi yang kecil (Suharti, 2015). Adapun teori lain yang menyatakan bahwa mayoritas investor di Indonesia beranggapan bahwa biaya atau dana yang dibutuhkan dalam berinvestasi pada reksa dana relative tidak mahal dan tidak mempengaruhi nilai investasi mereka (Bernadus Dwiprakarsa, 2016).

Hal ini dibuktikan oleh adanya keuntungan dalam berivestasi reksa dana Buka reksa dari,

https://m.bukalapak.com/bukareksa, yang menyatakan bahwa:

"Minimum dana investasi sangat terjangkau, Dana minimum untuk investasi di mulai dari Rp 10.000 saja. Sangat terjangkau di bandingkan investasi minimum Reksa Dana pada umumnya".

Artinya, modal awal atau dana yang akan dibutuhkan investor dalam melakukan investasi reksa dana di BukaLapak ini relative tidak mahal dan sangat terjangkau. 
Hal tersebut tidak berbeda dengan penelitian yang dilakukan oleh Meilinda yang menyatakan bahwa investasi reksa dana disini membuka peluang bagi investor kecil agar dapat melakukan investasi pada pasar modal dengan modal yang sangat sedikit sekali dan terjangkau (meilinda, 2010).

\section{Ucapan Terima Kasih}

Terselesaikannya penulisan Riset Penelitian "Minat Investor Muda dalam Berinvestasi Reksa Dana di BukaLapak" ini dengan baik, tidaklah mungkin tanpa bantuan, dukungan dan bimbingan dari berbagai pihak. Pada kesempatan ini, peneliti ingin menyampaikan ucapan terima kasih khususnya kepada: Bapak Kharis Fadlullah Hana, M.E, Selaku Dosen Pengampu Mata Kuliah Riset Pasar Modal, yang telah senantiasa membimbing kami dalam penyelesaian penelitian ini. Dan kepada para Investor Reksa Dana BukaLapak yang sudah berkenan meluangkan waktunya untuk membantu penyelesaian penelitian kami.

\section{PENUTUP}

\section{Kesimpulan}

Berdasarkan hasil dan analisis data dapat disimpulkan bahwa minat investor muda dalam berinvestasi reksa dana pada aplikasi BukaLapak saat ini sedang ramai di tengah masyarakat. Investasi tersebut menjadi salah satu pilihan dalam berinvestasi dikarenakan prosedur pelaksanaannya sangat efisien yang disebabkan oleh kemurahan dan kemudahannya. Hal ini sesuai dengan anggapan sebagian investor muda reksa dana pada penelitian ini mengenai persepsi dan minat investor muda Reksa Dana BukaLapak dalam berinvestasi di sebabkan oleh faktor kemudahan dalam operasional investasi Reksa Dana Bukalapak ini, karena operasionalnya sangatlah mudah dan sederhana cukup dengan memasukan data yang dibutuhkan saja dan seperti transaksi pada umumnya. Selain faktor kemudahan, adapun faktor lain yakni harga atau modal yang terjangkau yang dibutuhkan dalam investasi Reksa Dana BukaLapak ini, hanya dengan dana minimum kurang dari Rp100.000 saja bisa melakukan investasi Reksa Dana BukaLapak.

\section{Saran}

Diharapkan untuk penelitian selanjutnya bisa menambah narasumber yang sudah berpengalaman dalam berinvestasi reksa dana pada aplikasi BukaLapak sehingga mendapatkan hasil yang lebih baik.

\section{DAFTAR PUSTAKA}

Aji Darusman. (2019). Pengaruh Media Online Terhadap Minat Belajar Siswa (Studi Kasus: Smk Islam Wijaya Kusuma. Litertatus, 1(1), 1-24.

Anggito, A., \& Setiawan, J. (2018). Metodologi Penelitian Kualitatif. CV Jejak.

Ary Satria Pamungkas, Herlina Budiono, Hendra Wiyanto, H. W. (2019). Pelatihan Pengenalan Investasi Reksa Dana untuk Pelajar SMK Ariya Metta. Abdamas, 133- 
140.

Aulia, M. Z. (n.d.). Reksa Dana Syariah Lembaga Keuangan Syariah dalam Ekonomi Islam. 1-10.

Bernadus Dwiprakarsa, C. F. D. (2016). Karakteristik Reksa Dana dan Kinerja Reksa Dana Saham di Indonesia. Jurnal Manajemen, 13(1), 94-116. https://doi.org/10.24912/je.v22i1.181

Edi, F. R. S. (2016). teori wawancara Psikodignostik. Leotika Prio.

Endang samsul arifin. (2017). kinerja reksadana saham syariah di indonesia. Jurnal Ekonomi Dan Bisnis, 17(1), 82-86.

Marselo Valentino Geovani Pariela. (2017). Wanprestasi Manajer Investasi Terhadap Investor Reksadana. SASI, 23, 129-135.

Md. Qamruzzaman. (2014). Comparative Study on Performance Evaluation of Mutual Fund Schemes in Bangladesh: An Analysis of Monthly Returns. Journal of Business Studies Quarterly, 5(4), 190.

Meilinda. (2010). Reksa Dana Sebagai Salah Satu Alternatif Investasi. Bina Ekonomi Majalah IImiah Fakultas Ekonomi Unpar, 14(1).
Munawaroh, S., \& Sugiyono. (2019). Hukum Investasi. CV Jakad Publishing.

Naili Rahmawati, A. T. F. (2016). Analisis Minat Investor Di Kota Serang Terhadap Investasi Syariah Pada Pasar Modal Syariah. lqtishaduna, $\quad 7(1), \quad$ 172-193. https://doi.org/10.32678/ijei.v7i1.7

Regina Singestecia. (2018). Partisipasi Politik Masyarakat Tionghoa dalam Pemilihan Kepala Daerah di Slawi Kabupaten Tegal. Unnes Political Science Journal, 2(1), 6372.

Suharismi Arikunto. (1995). Dasar-dasar Research. Tarsoto.

Suharti, T. (2015). Portofolio Turnover dan Net Asset dengan Return Pasar sebagai Variabel Moderating, Expense Ratio, Cash dan Subscription Fee terhadap Kinerja Reksadana Periode 2009-2012. In Bisnis Strategi, 24, (1), 1-19.

Tiar Lina Situngkir. (2019). Sosialisasi Pengenalan Reksadana Sebagai Wadah Investasi Bagi lbu Rumah Tangga. Abdimas Universal, 1(1), 58-62.

https://m.bukalapak.com/bukareksa 